\title{
Relationship between Obesity and Maximal Insulin-stimulated Glucose Uptake In Vivo and In Vitro in Pima Indians
}

\author{
C. Bogardus, S. Lillioja, D. Mott, G. R. Reaven, \\ A. Kashiwagi, and J. E. Foloy \\ Phoenix Clinical Research Section, National Institute of Arthritis, \\ Diabetes, Digestive, and Kidney Diseases, National Institutes of \\ Health, Phoenix, Arizona 85016
}

bstract. Previous studies have left unanswered whether human obesity, independent of glucose intolerance, is associated with a "postreceptor" defect in insulin action. We have studied the relationship between the degree of obesity (as estimated by underwater weighing) and the maximal insulin-stimulated glucose disposal rate (M) in vivo in 52 glucose-tolerant Pima Indian males. The relationship was examined independently of differences in age and maximal oxygen uptake (an estimate of "physical fitness"). The maximal insulin-stimulated glucose transport rate (MTR) was also measured in isolated abdominal adipocytes from the same subjects to determine whether differences in $\mathbf{M}$ could be explained by differences in glucose transport. The results showed that there was a large variance in $M$ and MTR among these glucosetolerant subjects. $M$ was better correlated with glucose storage rates than with oxidation rates, as estimated by indirect calorimetry. The most obese subjects had only a 20\% lower mean M and 30\% lower MTR than the most lean subjects. The lower $M$ in the obese subjects was due to both lower glucose oxidation and storage rates. There was no significant, independent correlation between age or degree of obesity and M or MTR. The maximal oxygen uptake $\left(\mathrm{VO}_{2}\right.$ max) appeared to independently account for $20 \%$ of the variance observed in M. MTR was only weakly correlated with $\mathrm{M}(r=0.36, P<0.02)$. We concluded that differences in $M$ in these glucose-tolerant subjects must be explained by factor(s) other than maximal oxygen uptake, age, maximal insulin-stimulated glucose transport in vitro, or degree of adiposity per se.

Received for publication 8 August 1983 and in revised form 10 November 1983.

J. Clin. Invest.

(c) The American Society for Clinical Investigation, Inc.

$0021-9738 / 84 / 03 / 0800 / 06 \$ 1.00$

Volume 73, March 1984, 800-805

\section{Introduction}

The hyperinsulinemic, euglycemic clamp technique, performed at supraphysiologic insulin concentrations, has been used to assess postbinding steps in insulin action in man in vivo $(1,2$, 3). By using this technique, Kolterman et al. (1) have reported decreased in vivo maximal insulin-stimulated glucose utilization rates in obese compared with lean subjects. In contrast, DeFronzo (2) reported that in vivo maximal insulin-stimulated glucose utilization rates were similar between lean and obese subjects. A possible explanation for the different results was that Kolterman et al. studied obese subjects with or without glucose intolerance (4), whereas DeFronzo studied only glucose-tolerant subjects. Olefsky et al. (5) have also reported a significant association between decreased maximal insulin-stimulated glucose utilization rates in vivo and in vitro in isolated abdominal adipocytes from obese subjects with and without glucose intolerance.

The present study was designed to provide additional data regarding the relationship between obesity and maximal insulinstimulated glucose utilization rates in vivo and in vitro. In male Pima Indians, obesity was estimated by densitometry, in vivo maximal insulin-stimulated glucose disposal was measured by using the euglycemic clamp technique, and in vitro maximal insulin action was determined in isolated abdominal adipocytes from the same subjects. To minimize differences in glucose tolerance as a possible confounding variable in the analysis of the relationship between obesity and insulin action, only Indians with normal glucose tolerance were studied. The relationship between obesity and insulin action in vivo and in vitro was defined independently of other factors that may effect insulin action, such as age (6) and maximal oxygen uptake (7), an estimate of "physical fitness."

\section{Methods}

Subjects. Physically untrained, male Pima Indians of the Gila River Indian Reservation who had previously been examined as part of an ongoing epidemiological study of the reservation population were asked to volunteer for the study. After written informed consent was obtained, all subjects were admitted to the clinical research ward, physically ex- 
amined, and a 12-lead electrocardiogram recorded. After an overnight fast, blood was drawn for complete blood count, liver function tests, blood-urea nitrogen, creatinine, electrolytes, calcium, total protein, and albumin. After at least $2 \mathrm{~d}$ of a weight-maintaining diet containing more than $200 \mathrm{~g}$ of carbohydrate, an oral glucose tolerance test was performed (4). Only the results of subjects with a normal physical examination, electrocardiogram, screening blood tests, and normal glucose tolerance (4) are reported. The characteristics of the 52 study subjects are shown in Table $\mathrm{I}$.

Body composition. The percent body fat of each volunteer was estimated by underwater weighing with correction for the simultaneously measured residual lung volume (8).

In vitro glucose transport in isolated adipocytes. After at least $3 \mathrm{~d}$ of the weight-maintaining diet, and after a 12 -h overnight fast, subcutaneous adipose tissue was removed from the lateral aspect of the hypogastrium, inferior to the umbilicus (McBurney's point), and isolated adipocytes were prepared by collagenase digestion as described previously in detail (9). Three subjects refused the biopsy so that adipocyte data is available on 49 of the 52 subjects. Adipose cell size was determined by sizing osmium-fixed cells on Coulter Electronic Cell counter (Coulter Electronics, Inc., Hialeah, FL) equipped with logarithmic range-expanded channelyzer as described previously (9). We have measured maximal insulin-stimulated glucose transport by a new method, the verification of which has been reported previously (9) for obese subjects. We have verified that this method is also valid in lean subjects (data not shown). In brief, isolated adipocytes (2\% lipocrit) were incubated in $500 \mu 15 \%$ albumin buffer in the presence of trace $(300 \mathrm{nM})$ amount of $0.1 \mu \mathrm{Ci}$ $\left[\mathrm{U}-{ }^{14} \mathrm{C}\right]$-D-glucose. The cell suspensions was incubated at $37^{\circ} \mathrm{C}$ for $1 \mathrm{~h}$ with continuously shaking at $40 \mathrm{cpm}$. The incubation was terminated by centrifuging a $400-\mu \mathrm{l}$ aliquot in a $550-\mu \mathrm{l}$ microfuge tube containing $100 \mu \mathrm{l}$ silicone oil, and the amount of radioactivity associated with the adipocytes (as well as the total radioactivity in the medium) was determined by scintillation counting. The glucose transport was expressed as the glucose clearance rate in femtoliter per cell per second (clearance $=$ volume in the medium times $\mathrm{cpm}$ in cells per cpm in medium).

Euglycemic clamp. After at least $4 \mathrm{~d}$ on a weight-maintaining diet and at $0600 \mathrm{~h}$ after a 10-h overnight fast, an intravenous catheter was placed in an antecubital vein for infusion of insulin, glucose, and [3- $\mathrm{H}^{3}$ ]glucose. A primed $(30 \mu \mathrm{Ci})$-continuous $(0.30 \mu \mathrm{Ci} / \mathrm{min})$ infusion of $\left[3-\mathrm{H}^{3}\right] \mathrm{glucose}$ was then begun and continued throughout the procedure. Another catheter was placed retrograde in a dorsal vein of the contralateral hand for blood withdrawal. The hand was kept in a warming box at

Table I. Subject Characteristics

\begin{tabular}{lcc} 
& Mean \pm SEM & \multicolumn{1}{c}{ Range } \\
\hline Age $(y r)$ & $24 \pm 1$ & $18-38$ \\
Body weight $(\mathrm{kg})$ & $98.0 \pm 4.0$ & $50.3-188.1$ \\
Height $(\mathrm{cm})$ & $172.2 \pm 0.7$ & $158.0-181.5$ \\
Body mass index $\left(\mathrm{kg} / \mathrm{m}^{2}\right)$ & $33.6 \pm 1.3$ & $18.5-63.2$ \\
Fasting plasma glucose $(\mathrm{mg} / 100 \mathrm{ml})$ & $86 \pm 1$ & $72-101$ \\
2 hr glucose $(\mathrm{mg} / 100 \mathrm{ml}) \dagger$ & $105 \pm 3$ & $64-139$ \\
Fasting insulin $(\mu \mathrm{u} / \mathrm{ml})$ & $30 \pm 2$ & $8-90$ \\
Percent body fat* & $29 \pm 1$ & $8-46$
\end{tabular}

* Percent body fat was determined by underwater weighing. † Glucose concentration 2 h after a 75 -g oral glucose load. $70^{\circ} \mathrm{C}$. After $2.5 \mathrm{~h}$, four blood samples were drawn over $30 \mathrm{~min}$ for [3- $\mathrm{H}^{3}$ ]glucose specific activity determination. An insulin infusion was then started, and after 160-200 min, this resulted in a mean plasma insulin concentration of $1881 \pm 54 \mu \mathrm{U} / \mathrm{ml}$ for all subjects (mean coefficient of variation $=6 \pm 0.4 \%$ ). This plasma insulin concentration has been shown to result in a maximal rate of in vivo glucose utilization in lean and obese subjects $(1,2,3) .4 \mathrm{~min}$ after the start of the insulin, a variable $20 \%$ glucose infusion was started to maintain the plasma glucose concentration at $\sim 90 \mathrm{mg} / 100 \mathrm{ml}$ for the entire $200 \mathrm{~min}$ of hyperinsulinemia. Blood for plasma glucose concentration was drawn every 5 min throughout the test. During the last 40 min of the test, the mean plasma glucose concentration was $91 \pm 1 \mathrm{mg} / 100 \mathrm{ml}$ (mean C.V. $=3.2 \pm 0.2 \%$ ). Blood for plasma insulin and $\left[3-\mathrm{H}^{3}\right]$ glucose specific activity was drawn every $10 \mathrm{~min}$ from 160 to $200 \mathrm{~min}$.

Indirect calorimetry. $1 \mathrm{~h}$ before the start of the insulin infusions, a clear, plastic, ventilated hood was placed over the subject's head. Room air was drawn through the hood and the flow rate measured by a pneumotachograph (Gould, Cleveland, Ohio). A constant fraction of expired air was withdrawn and analyzed for oxygen and carbon dioxide content. The oxygen analyzer was a zirconium cell analyzer (Applied Electrochemistry, Sunnyvale, CA) and the carbon dioxide analyzer was an infrared analyzer (Applied Electrochemistry). The analyzers and flowmeter were connected to a desktop computer (Hewlett-Packard Co., Palo Alto, CA). This recorded continuous, integrated calorimetric measurements every $5 \mathrm{~min}$ for the hour before and for the duration of the euglycemic clamp. The protein oxidation during the test was estimated from the urinary urea production rate. The nonprotein respiratory quotient was then calculated and the substrate oxidation rates determined from the tables of Lusk (10).

Maximal oxygen uptake determinations. A graded exercise test was performed the day after the euglycemic clamp procedure by using intermittent work-bouts on a treadmill. Each test was started at 0 degrees elevation and involved walking at $1.5 \mathrm{mph}$. The elevation and speed of the treadmill were gradually increased. After $4 \mathrm{~min}$ at each work level, the subject sat down until the heart rate was $<120$ beats per minute and he had subjectively recovered. The test continued until the patient was subjectively exhausted, the heart rate reached 200 beats per minute, or there was no further increase in the oxygen uptake $\left(\mathrm{VO}_{2}\right)^{1}(11,12)$. The oxygen uptake was determined during the last $30 \mathrm{~s}$ to $1 \mathrm{~min}$ of each work-bout. The subject was connected to a low-resistance mouthpiece or "J" valve (Warren E. Collins, Inc., Braintree, MA). After 1 min of adaptation, the expired air was collected in a 120-liter Tissot spirometer (Warren E. Collins, Inc.). During the collection period, a sample of expired air was continuously drawn and analyzed for oxygen and carbon dioxide as described above. The average fraction of $\mathrm{O}_{2}$ and $\mathrm{CO}_{2}$, the minute ventilation, oxygen uptake, $\mathrm{CO}_{2}$ production, and respiratory quotient were calculated by an on-line Hewlett Packard 85 computer and printed out at the end of each collection. $\mathrm{VO}_{2}$ max was defined as the highest $\mathrm{VO}_{2}$ recorded during the exercise test.

Calculations. The appearance rate $(\mathrm{Ra})$ of glucose in the plasma during the euglycemic clamp was calculated from the blood $\left[3-\mathrm{H}^{3}\right]$ glucose specific activities by using the nonsteady state equations of Steele (13). The endogenous glucose production rate equals the difference between the rate of exogenous glucose infusion and the Ra determined from Steele's equations. If the $\mathrm{Ra}$ was equal to or less than the exogenous glucose infusion rate, the endogenous glucose production rate was as-

1. Abbreviations used in this paper: $\mathrm{M}$, total maximal insulin-stimulated glucose disposal; MTR, maximal insulin-stimulated glucose transport by isolated adipocytes; $\mathrm{VO}_{2}$, oxygen uptake. 
sumed to be completely suppressed. In this study, this occurred in all subjects so that the total glucose disposal rate $=$ exogenous glucose infusion rate. The mean exogenous glucose infusion rate was calculated for each 20 min between 160-200 min during the euglycemic clamp and then averaged to calculate the mean glucose disposal rate or " $M$ " value. The insulin-stimulated carbohydrate oxidation rates were calculated from the indirect calorimetric data by averaging the data for the last $\mathbf{4 0} \mathrm{min}$ of the insulin infusion, i.e., also from 160 to $200 \mathrm{~min}$ during the euglycemic clamp. The carbohydrate storage rate was estimated by subtracting the carbohydrate oxidation rate from the mean total glucose disposal rate.

Analytical methods. The plasma glucose concentration was measured by the glucose oxidase method by using a Beckman glucose analyzer (Beckman Instruments, Inc., Fullerton, CA). Plasma insulin concentrations were determined by the Herbert modification (14) of the radioimmunoassay of Berson and Yalow (15). The tritiated glucose specific activity in blood samples was performed as described by others (16) by using perchloric acid to precipitate the protein.

Statistics. All data are expressed as the means \pm SEM. All statistical analyses were calculated by using statistical analysis system (SAS Institute, Inc., Cary, NC). Simple correlations are Person product moment correlations and partial correlations were calculated using the SAS general linear models procedure.

\section{Results}

The mean $( \pm$ SEM) and range of values of all the metabolic variables measured are listed in Table II. Seventeen subjects, one third of the study population, were within two standard deviations of the mean percent body fat determined by similar methods in Caucasian males of similar age (17), and therefore, can be considered to have a "normal" body composition. No

Table II. Maximal Oxygen Uptake, Maximal Insulin-Stimulated Glucose Disposal Rates during the Euglycemic Clamp, and Maximal Insulin-Stimulated Glucose Transport Rates in Isolated Abdominal Adipocytes

\begin{tabular}{|c|c|c|c|}
\hline & $\mathrm{n}$ & Mean + SEM & Range \\
\hline $\begin{array}{l}\text { Maximal oxygen uptake } \\
\quad\left(\mathrm{ml} / \mathrm{O}_{2} / \mathrm{kg}-\mathrm{fm} \text { per } \mathrm{min}\right) \\
\text { Euglycemic clamp procedure: }\end{array}$ & 37 & $49.2 \pm 0.7$ & $39.1-60.1$ \\
\hline $\begin{array}{l}\text { Maximal insulin-stimulated } \\
\text { total glucose disposal rate } \\
(\mathrm{mg} / \mathrm{kg}-\mathrm{ffm} \text { per } \mathrm{min})\end{array}$ & 52 & $10.82 \pm 0.34$ & $5.80-16.80$ \\
\hline $\begin{array}{l}\text { Maximal insulin-stimulated } \\
\text { glucose oxidation rate } \\
\text { (mg/kg-ffm per min) }\end{array}$ & 50 & $4.89 \pm 0.13$ & $3.11-7.37$ \\
\hline $\begin{array}{l}\text { Maximal insulin-stimulated } \\
\text { glucose storage rate } \\
\text { (mg/kg-ffm per min) }\end{array}$ & 50 & $6.07 \pm 0.27$ & $2.11-12.02$ \\
\hline $\begin{array}{l}\text { Isolated abdominal adipocytes: } \\
\text { Maximal insulin-stimulated } \\
\text { glucose transport rate } \\
(\mathrm{fl} / \mathrm{s} \text { per } \mathrm{cell})\end{array}$ & 49 & $110 \pm 9$ & $26-284$ \\
\hline
\end{tabular}

ffm, fat-free mass. subject was less than two standard deviations below the mean of the Caucasians; therefore, the remaining subjects may be considered to have increased percent body fat, or are "obese." More importantly, as can be seen in Fig. 1, the subjects were distributed over a broad range of percent fat. It can be seen that there also was a wide range of values for total maximal insulin-stimulated glucose disposal rates in vivo (M), glucose storage rates, and maximal insulin-stimulated glucose transport by isolated adipocytes (MTR). In contrast, there was less variance in maximal insulin-stimulated glucose oxidation rates and in maximal oxygen uptakes.

The relationship between obesity and $M$ values is shown in Figure $1 A$. There was a weak, statistically significant negative linear correlation between the percent body fat and $\mathbf{M}(r$
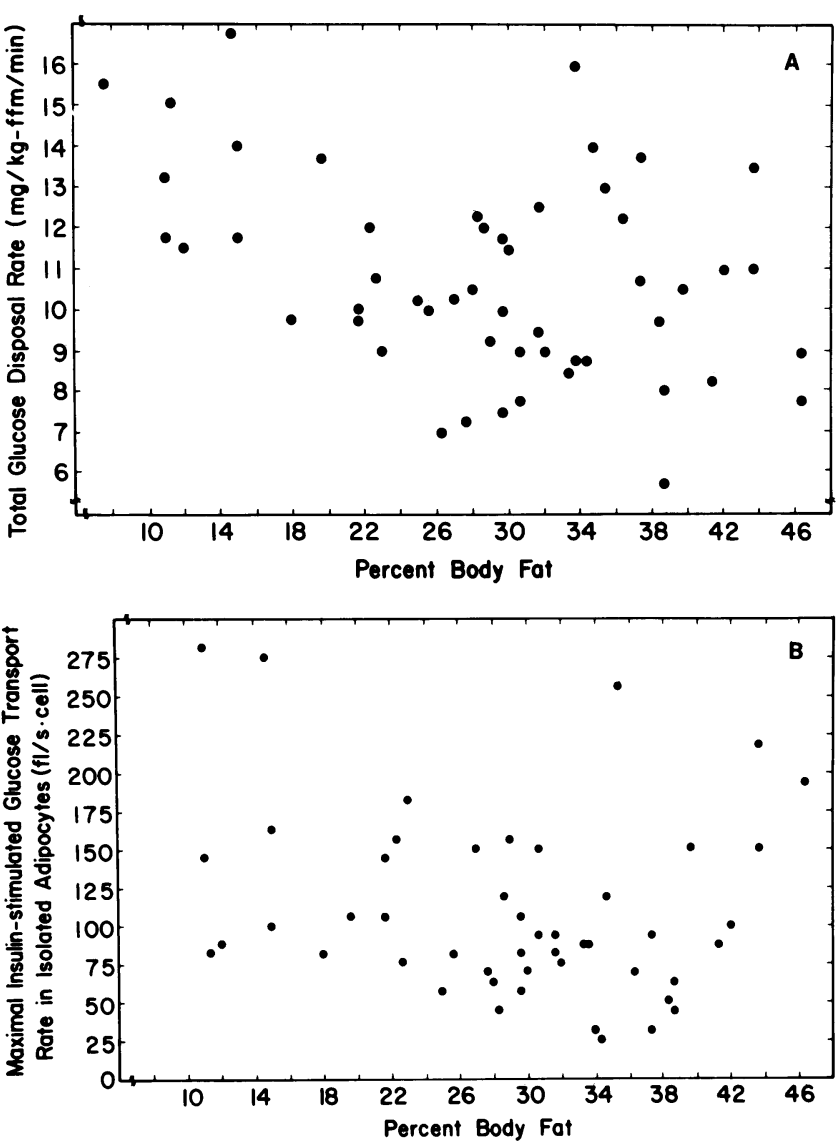

Figure 1. (A) Relationship between maximal insulin-stimulated glucose disposal rate (expressed as milligrams per kilogram of fat-free mass per minute) during the euglycemic clamp procedure and percent body fat. Percent body fat and fat-free mass are as determined by the underwater weighing technique. Mean $( \pm$ SEM) steady state insulin concentration was $1881 \pm 54 \mu \mathrm{U} / \mathrm{ml} . \mathrm{r}=-0.40 ; P<0.005$; $\mathrm{n}=52$. $(B)$ The relationship between the maximal insulin-stimulated glucose transport rate in isolated adipocytes (expressed as femtoliters per second per cell) and the percent body fat. Percent body fat is determined by underwater weighing. $\mathrm{r}=-0.19 ; P=\mathrm{NS}, \mathrm{n}=49$. $\mathrm{ffm}$, fat-free mass. 
$=-0.40, P<0.005)$. $\mathrm{M}$ was better correlated with the glucose storage rate $(r=0.93, P<0.001)$ than with oxidation rates ( $r=0.66, P<0.001)$. Percent body fat was weakly correlated with the maximally insulin-stimulated glucose oxidation rate $(r$ $=-0.39, P<0.05)$ and the glucose storage rates $(r=-0.30$, $P<0.02)$. However, there was no significant linear correlation between MTR and percent body fat (Fig. $1 B$ ).

To further evaluate the effect of obesity on maximal insulinstimulated glucose disposal in vivo and on glucose transport in vitro, we formed two extreme groups of the most lean (mean percent body fat $=13 \pm 1 \%$ ) and the most obese subjects (mean percent body fat $=38 \pm 1 \%)$. The lean group $(n=10)$ consisted of subjects with a percent body fat $<20 \%$, and comprised 10 individuals. There were 20 subjects in the obese group, all with a percent body fat $>32 \%$. The results of these comparisons are seen in Fig. 2, and the data in the left panel indicate $M$ was reduced by about $20 \%$ in the most obese group. Although this was a small difference, it was statistically significant $(P<0.05)$. Further inspection of the data in the left panel shows that this difference was due to a reduction in both the mean glucose oxidation and storage rate. The mean reduction in MTR in adipocytes isolated from the obese group were actually greater than the fall in $M$ value, but because of the large individual variance, this effect of obesity was of marginal significance $(P=0.11)$ (Fig. $2 B$ ).

Maximal oxygen uptake was determined in 37 of the 52 subjects and the relationship between $\mathrm{VO}_{2}$ max and $\mathrm{M}$ is shown in Fig. 3. There was a significant positive linear correlation between $\mathrm{VO}_{2}$ max and $\mathrm{M}(r=0.56, P<0.001)$. Similarly, $\mathrm{VO}_{2}$ max correlated positively with the insulin-stimulated glucose

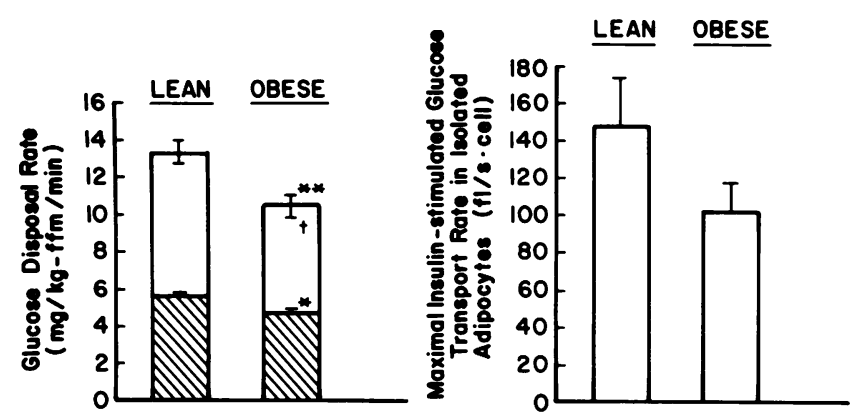

Figure 2. (Left) Comparison of the mean total glucose disposal rate (expressed as milligrams per kilogram of fat-free mass per minute), glucose oxidation rate (hatched areas), and glucose storage rate (open areas) during the euglycemic clamp procedure, between the 20 most obese subjects (mean percent body fat $=38 \pm 1 \%$ ) subjects and the 10 most lean subjects (mean percent body fat $=13 \pm 1 \%$ ). (Right) Comparison of the maximal insulin-stimulated glucose transport rate in isolated adipocytes from the same subjects. The glucose transport rate is expressed as femtoliters per second per cell. *Significant difference between groups $(P<0.05)$ in glucose oxidation rates. †Significant difference between groups $(P<0.05)$ in glucose storage rates. ${ }^{* *}$ Significant difference between groups $(P<0.05)$ in the total glucose disposal rate. ffm, fat-free mass.

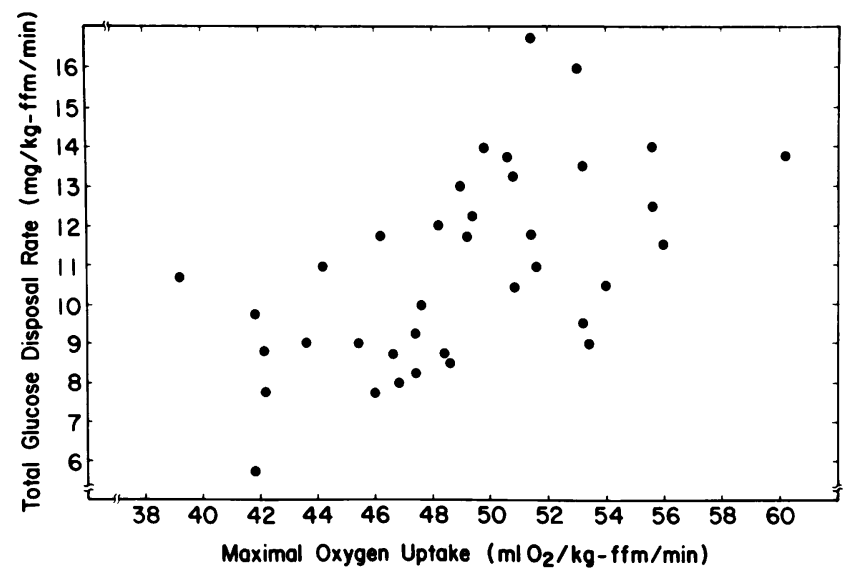

Figure 3. Relationship between the total insulin-stimulated glucose disposal rate (expressed as milligrams per kilogram of fat-free mass per minute) during the euglycemic clamp procedure and maximal oxygen uptake (expressed as milliliters of oxygen consumed per kilogram of fat-free mass per minute) in $\mathbf{3 7}$ of the $\mathbf{5 2}$ male Indians. Mean ( \pm SEM) steady state insulin concentration was $1881 \pm 54$ $\mu \mathrm{U} / \mathrm{ml}$.

oxidation rate $(r=0.51, P<0.002)$ and glucose storage rate $(r=0.47, P<0.005)$. However, no correlation was seen between $\mathrm{VO}_{2} \max$ and MTR in vitro in isolated adipocytes. The mean $\mathrm{VO}_{2}$ max of the 20 most obese subjects was significantly $(P$ $<0.05$ ) lower than that of the 10 most lean subjects, $48.2 \pm 1.0$ $\mathrm{ml} \mathrm{O}_{2} / \mathrm{kg}$ fat-free mass per min vs. $52.7 \pm 1.5 \mathrm{ml} \mathrm{O}_{2} / \mathrm{kg}$ fat-free mass per min, respectively.

Increasing age was negatively correlated with total $\mathbf{M}(r$ $=-0.32, P<0.02$ ). Age was also significantly negatively correlated with the glucose storage rate $(r=-0.30, P<0.04)$, but not with the glucose oxidation rate $(r=-0.20, P=0.17)$. The MTR in vitro did not significantly correlate with age.

The linear correlations between percent body fat, $\mathrm{VO}_{2} \max$, and age, and the measures of insulin action were then examined by partial correlation analyses. These analyses were done only on the 37 subjects for whom there was data for $\mathrm{M}$, percent body fat, and $\mathrm{VO}_{2}$ max.

These results are seen in Table III, and the important conclusions can be drawn from these data. First, it is apparent that the simple correlation coefficients between percent body fat and either $\mathrm{VO}_{2}$ max, age, and in vivo insulin action declined when the individual correlations were adjusted for the effect of the other two variables. Secondly, it can be seen that only the $\mathrm{VO}_{2}$ max remained significantly correlated with the measures of in vivo insulin action after these adjustments were made. Thus, neither obesity nor age appear to be independently correlated with in vivo maximal insulin-stimulated glucose disposal, storage, or oxidation rate.

The relationship between the MTR of glucose by isolated adipocytes and the $M$ value in vivo is shown in Fig. 4 . There was a weak, positive linear correlation between these in vitro and in vivo estimates of insulin action $(r=0.36, P<0.02)$. 
Table III. Simple and Partial Correlation Coefficients between Percent Body Fat, $\mathrm{VO}_{2}$ max, Age and the Insulin-stimulated Total Glucose Disposal Rate, Glucose Oxidation Rate, and Glucose Storage Rate during the Euglycemic Clamp Procedure

\begin{tabular}{|c|c|c|c|c|c|c|}
\hline & \multicolumn{2}{|c|}{ Percent body fat (\%) } & \multicolumn{2}{|c|}{$\mathrm{vO}_{2} \max (\mathrm{ml} \mathrm{O} / \mathrm{kg}$-ffm per min) } & \multicolumn{2}{|c|}{ Age $(y r)$} \\
\hline & Simple & Partial & Simple & Partial & Simple & Partial \\
\hline $\begin{array}{l}\text { Total glucose disposal rate } \\
(\mathrm{mg} / \mathrm{kg}-f f m \text { per } \mathrm{min})\end{array}$ & $\begin{array}{l}-0.37 \\
(P<0.03)\end{array}$ & $\begin{array}{l}-0.25 \\
\text { (NS) }\end{array}$ & $\begin{array}{l}0.56 \\
(P<0.01)\end{array}$ & $\begin{array}{l}0.48 \\
(P<0.01)\end{array}$ & $\begin{array}{l}0.37 \\
(P<0.03)\end{array}$ & $\begin{array}{l}-0.25 \\
\text { (NS) }\end{array}$ \\
\hline $\begin{array}{r}\text { Glucose oxidation rate } \\
(\mathrm{mg} / \mathrm{kg}-f f m \text { per } \mathrm{min})\end{array}$ & $\begin{array}{l}-0.32 \\
(P<0.05)\end{array}$ & $\begin{array}{l}-0.12 \\
\text { (NS) }\end{array}$ & $\begin{array}{l}0.46 \\
(P<0.01)\end{array}$ & $\begin{array}{l}0.47 \\
(P<0.02)\end{array}$ & $\begin{array}{l}-0.23 \\
\text { (NS) }\end{array}$ & $\begin{array}{l}-0.10 \\
\text { (NS) }\end{array}$ \\
\hline $\begin{array}{l}\text { Glucose storage rate } \\
(\mathrm{mg} / \mathrm{kg}-f f m \text { per } \mathrm{min})\end{array}$ & $\begin{array}{l}-0.28 \\
\text { (NS) }\end{array}$ & $\begin{array}{l}-0.21 \\
\text { (NS) }\end{array}$ & $\begin{array}{l}0.53 \\
(P<0.01)\end{array}$ & $\begin{array}{l}0.36 \\
(P<0.05)\end{array}$ & $\begin{array}{l}-0.35 \\
(P<0.04)\end{array}$ & $\begin{array}{l}-0.24 \\
\text { (NS) }\end{array}$ \\
\hline
\end{tabular}

$\mathrm{n}=\mathbf{3 7}$ for all comparisons. $\mathrm{fm}$, fat-free mass.

This relationship was not changed by adjusting for differences in $\mathrm{VO}_{2}$ max, age, and percent body fat.

\section{Discussion}

The results of this study showed that obesity had a relatively minor effect, if any, on in vivo maximal insulin-stimulated glucose disposal rates in male Pima Indians with normal glucose tolerance. Specifically, there was only a relatively weak simple correlation between percent body fat and values for maximal insulin-stimulated glucose utilization $(r=-0.40, P<0.005)$, glucose oxidation $(r=-0.39, P<0.05)$, and glucose storage rates $(r=-0.30, P<0.02)$. Furthermore, when adjustments were made for $\mathrm{VO}_{2} \max$ and age, the relationships between percent body fat and the various measures of in vivo insulin action were no longer statistically significant. In support of the

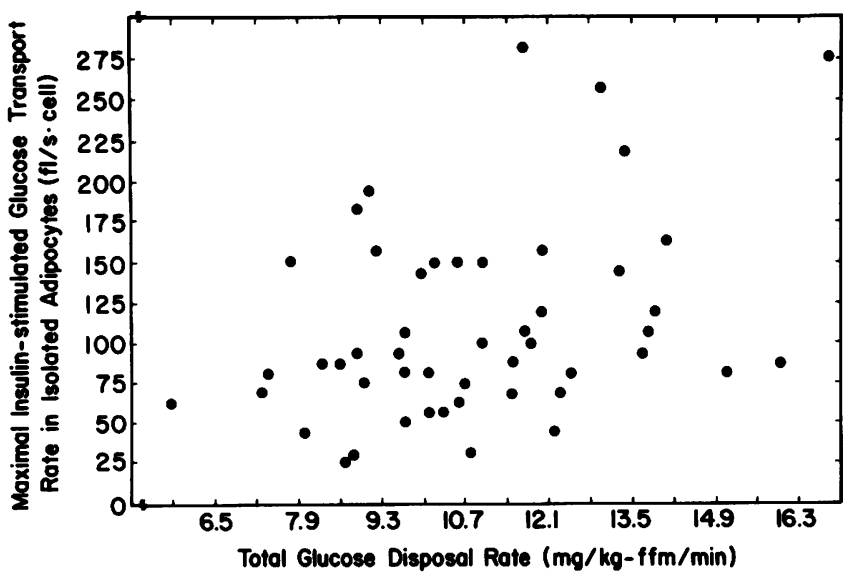

Figure 4. Relationship between the total insulin-stimulated glucose disposal rate (expressed as milligrams per kilogram of fat-free mass per minute) during the euglycemic clamp procedure and the maximal insulin-stimulated glucose transport rate in isolated abdominal adipocytes from the same subjects. Mean ( \pm SEM) steady state plasma insulin concentration was $1881 \pm 54 \mu \mathrm{U} / \mathrm{ml}$. ffm, fat-free mass. marginal impact of obesity was the observation that the mean $M$ was only $20 \%$ lower in a group of extremely obese subjects compared with a group of lean individuals, despite the fact that the obese individuals had a three times greater percent body fat. Changes in maximal insulin-stimulated glucose transport by isolated adipocytes need not mirror in vivo glucose utilization, but in the present case, both estimates of the effect of obesity on insulin action provided similar information. Indeed, the effect of obesity on maximal insulin-stimulated glucose transport by isolated adipocytes was even less pronounced than its effect on in vivo glucose utilization. Specifically, there was not even a statistically significant simple correlation between percent body fat and MTR, and the difference between MTR of adipocytes isolated from the most obese and the most lean subjects was also not statistically significant. Thus, we could not document any significant effect of obesity on in vitro maximal insulinstimulated glucose transport.

These results are in contrast with previously reported experimental data $(1,5)$. However, the characteristics of the subjects in the previous studies and ours are different. We have studied Pima Indians and the earlier studies were of Caucasians. Secondly, and we believe more importantly, approximately half of the obese patients studied by Kolterman et al. (1) were glucose intolerant. Also, it is apparent from our results that there is a large variance in $M(5.80-16.80 \mathrm{mg} / \mathrm{kg}$-fat-free mass per min) and MTR (26-284 $\mathrm{fl} / \mathrm{sec}$ per cell) in glucose tolerant subjects. Therefore, depending upon the subgroup of subjects studied, evidence for a "postreceptor" defect in insulin action may or may not be found. This may also explain why DeFronzo (2) found no difference between the mean $M$ of 8 obese subjects compared with that of 10 lean controls. Previous studies have also not taken into consideration the relationship between $M$ and $\mathrm{VO}_{2} \max$. $\mathrm{VO}_{2}$ max can be used as an estimate of a person's ability to perform work (12) and therefore can be viewed as providing an estimate of "physical fitness." In addition, differences in $\mathrm{VO}_{2}$ max can have a genetic basis (18). Regardless, the current results documented a significant correlation between $\mathrm{VO}_{2}$ max and maximal insulin-stimulated glucose utilization, 
storage, and oxidation, which was independent of age or obesity. Given these findings, and an earlier report of an independent correlation between $\mathrm{VO}_{2} \max$ and $\mathrm{M}$ at lower insulin concentrations (7), it is apparent that previous estimates of the deleterious effect of obesity on insulin action may have been confounded by the fact that obese subjects frequently have lower maximal oxygen uptake rates compared with lean subjects.

Although it was not the purpose of the current study, we observed a large variance in the individual values for $M$ and MTR of the 52 Pima males who make up the study population. This may help explain why we observed only a very weak correlation between $M$ and MTR. This weak correlation contrasts with a previous report (5) that showed a good correlation between these parameters in a smaller group of lean and obese Caucasians. Again, differences in the glucose tolerance of the subjects in the two studies may be the reason for the different results. In addition, since there is such a large variance in $M$ in obese subjects, different results may be obtained depending on the subgroup studied. The weak correlation between in vitro glucose transport and in vivo glucose disposal should not be interpreted, however, as evidence that glucose transport cannot be an important "postreceptor" rate-limiting step for insulin action in vivo. It has been shown previously that diabetic patients have lower in vitro glucose transport rates and M's than glucose-tolerant, weightmatched subjects and that both parameters are increased following insulin therapy $(9,19,20,21)$, suggesting that transport may be an important rate-limiting step for insulin action in vivo under some conditions.

In conclusion, we were able to account for very little of the variance observed in the maximal insulin-stimulated glucose disposal rate in vivo in glucose-tolerant subjects. The cause of this variance in insulin action, at these maximally stimulating insulin concentrations, remains largely unexplained. Our data suggest that further studies to define "postreceptor" defects in insulin action in vivo should focus on the cause of a decreased glucose storage rate rather than differences in oxidation rates, since $\mathbf{M}$ has more highly correlated with insulin-stimulated glucose storage rates than with glucose oxidation rates.

\section{Acknowledgments}

We thank Ms. Marjorie Robinson and the nursing staff of the Phoenix Clinical Research Section for nursing support; Verna Kuwanhoyioma for secretarial help; Thomas Huecksteadt, Karen Stone, Inge Harper, Vera Rodriguez, Pamela Thuillez, and David Brady for technical assistance. Most of all, we thank the Indian volunteers.

\section{References}

1. Kolterman, O. G., J. Insel, M. Saekow, and J. M. Olefsky. 1980. Mechanisms of insulin resistance in human obesity. Evidence for receptor and postreceptor defects. J. Clin. Invest. 65:1272-1284.

2. DeFronzo, R. A. 1982. Insulin secretion, insulin resistance, and obesity. Int. J. Obesity. 6(Suppl. 1):73-82.
3. Rizza, R. H., L. J. Mandarino, and J. E. Gerich. 1981. Doseresponse characteristics for effects of insulin on production and utilization of glucose in man. Am. J. Physiol. 240:E630-E639.

4. National Diabetes Data Group. 1979. Classification and diagnosis of diabetes mellitus and other categories of glucose intolerance. Diabetes. 28:1039-1057.

5. Olefsky, J. M., O. G. Kolterman, and J. A. Scarlett. 1982. Insulin action and resistance in obesity and noninsulin-dependent type II diabetes mellitus. Am. J. Physiol. 243:E15-E30.

6. DeFronzo, R. A. 1979. Glucose intolerance and aging. Evidence for tissue insensitivity to insulin. Diabetes. 28:1095-1101.

7. Rosenthal, M., M. W. L. Haskell, R. Solomon, A. Widstrom, and G. M. Reaven. 1983. Demonstration of a relationship between level of physical training and insulin-stimulated glucose utilization in normal humans. Diabetes. In press.

8. Goldman, R. F., and E. R. Buskirk. 1961. Body volume measurements by underwater weighing: a description of a method. In Techniques for Measuring Body Composition. J. Brozek and A. Herschel, editors. National Academy of Sciences, Washington, DC. 78-89.

9. Kashiwagi, A., M. A. Verso, J. Andrews, B. Vasquez, G. Reaven, and J. E. Foley. 1983. In vitro insulin resistance of human adipocytes isolated from subjects with noninsulin-dependent diabetes mellitus. $J$. Clin. Invest. 72:1246-1254.

10. Lusk, G. 1924. Animal calorimetry. Analysis of oxidation of mixtures of carbohydrate and fat. J. Biol. Chem. 59:41-42.

11. Shephard, R. J., C. Allen, A. J. S. Benode, C. T. M. Davies, P. E. diPrampero, R. Hedman, J. E. Merriman, K. Mylire, and R. Simmons. 1968. The maximum oxygen uptake. WHO. Chron. 38:757784.

12. Astrand, P.-O., and Radahl, K. 1970. Textbook of Work Physiology: Physiological Basis of Exercise. McGraw-Hill, Inc., New York. 447-477.

13. Steele, R. 1959. Influences of glucose loading and of injected insulin on hepatic glucose output. Ann. NY Acad. Sci. 82:420-430.

14. Herbert, V., K. Lau, C. W. Gottlieb, and S. J. Bleicher. 1965. Coated charcoal immunoassay of insulin. J. Clin. Endocrinol. Metabol. 25:1375-1384.

15. Yalow, R. S., and S. A. Berson. 1960. Immunoassay of endogenous plasma insulin in man. J. Clin. Invest. 39:1157-1167.

16. Best, J. D., R. G. Judzewitsch, M. A. Pfeifer, J. C. Beard, J. B. Halter, and D. Porte, Jr. 1982. The effect of chronic sulfonylurea therapy on hepatic glucose production in non-insulin dependent diabetes. $\mathrm{Di}$ abetes. 31:333-338.

17. Chumlea, W. C., A. F. Roche, R. M. Siervogel, J. L. Knittle, and P. Webb. 1981. Adipocytes and adiposity in adults. Am. J. Clin. Nutr. 34:1798-1803.

18. Klissouras, V. 1971. Heritability of adaptive variation. J. Appl. Physiol. 31:338-344.

19. Scarlett, J. A., R. S. Gray, J. Graffin, J. M. Olefsky, and O. G. Kolterman. 1982. Insulin treatment reverses the insulin resistance of type II diabetes mellitus. Diabetes Care. 5:353-363.

20. Andrews, J., I. Klimes, B. Vasquez, and M. Nagulesparan. 1982. Can one month strict glycemia control in non-insulin dependent diabetes return insulin action to normal. American Diabetes Association, 42nd Annual Meeting, San Francisco. 59A.

21. Greenfield, M., C. Landinois, L. Doberne, and H. Vreman. 1982. Metabolic effects of intensive insulin therapy in patients with non-insulin dependent diabetes (NIDDM). American Diabetes Association, 42nd Annual Meeting, San Francisco. 58A. 